\title{
Designing self-monitoring warm-up strategy with blog- based learning system to support knowledge building
}

\author{
Yih-Ruey Juang* \\ Department of Information Management \\ Jinwen University of Science and Technology, Taiwan \\ E-mail: yrjuang@just.edu.tw
}

\section{Chih-Yueh Chou}

Department of Computer Science \& Engineering

Yuan Ze University, Taiwan

E-mail: cychou@ saturn.yzu.edu.tw

\section{James Chan}

Department of Information Management

Jinwen University of Science and Technology, Taiwan

E-mail: jameschan@just.edu.tw

*Corresponding author

\begin{abstract}
Preparing lessons before class is widely recognized as an effective means of increasing student motivation for classroom activities and learning outcome. However, the unclear status of lesson preparation generally discourages teachers and students from maintaining this effective learning strategy. This study applied the self-explanation theory and reading comprehension strategies to design a lesson warm-up mechanism that scaffolds knowledge building. A set of corresponding supporting tools were developed into a blog-based learning system (BBLS) to implement the warm-up process. Results of a teaching experiment reveal positive effects of the tools on learning achievement, recall of old knowledge, connection between old and new knowledge, and understanding of new knowledge.
\end{abstract}

Keywords: Self-monitoring; WIRE model; Knowledge building; Blog-based learning System (BBLS)

Biographical notes: Yih-Ruey Juang is an assistant professor of the Department of Information Management in Jinwen University of Science \& Technology. He received the PhD from the Department of Computer Science and Information Engineering in National Central University, Jhoung-Li, Taiwan. His research interests are focused on computer supported collaborative learning, interactive learning technology, e-Learning system development, computer assisted programming learning, social learning, and game-based learning.

Chih-Yueh Chou is an associate professor of the Department of Computer Science and Engineering in Yuan Ze University, Taiwan. His research interests include simulated learning companion, intelligent educational agents, gamebased learning, computer assisted programming learning, and social learning 


\begin{abstract}
theories and systems.
James Chan is a lecturer of Department of Information Management in Jinwen University of Science \& Technology. He received both MS and BS degrees in Computer Science from Tamkang University, Taiwan. Before working in university, he had many industry working experiences for several years in embedded system development and project management. His main research interests are operating systems, system programming, and network security.
\end{abstract}

\title{
1. Introduction
}

As is widely recognized, preparing lessons before class is an effective means of increasing student motivation for classroom activities and learning outcome. Most teachers and students agree on the importance of preparing lessons before class as essential in engaging students in classroom activities and facilitating knowledge building. However, the unclear status of lesson preparation generally discourages teachers and students from maintaining this effective learning strategy. Most teachers find it difficult to determine the previous knowledge of students and the obstacles that students face. Meanwhile, most students have difficulty in comprehending learning materials and identifying what prerequisite knowledge must be reviewed to fully grasp new lessons.

The Just-in-Time Teaching (JiTT) (Novak, Patterson, Garvin, \& Christian, 1999) approach evaluates learners' preliminary understanding of a new lesson by reviewing their preparatory assignments submitted online and, then, organizing classroom lessons. However, related literature has identified some limitations of this approach. Teachers often feel overwhelmed in reviewing all preparatory assignments submitted online and then preparing teaching content - in only two hours. Additionally, following classroom activities, teachers must prepare a short quiz for the next lesson in a relatively short time (Cashman \& Eschenbach, 2003; Howard, 2004; Benedict \& Anderton, 2004). Moreover, students are generally hesitant to read materials only for completing the warm-up quiz, instead opting to "simply skim the selection to find the detail that answers the multiple choice questions and provide a minimal response to the short-answer question (Howard, 2004)." Superficial warm-up lessons contribute only slightly to classroom learning. Finally, teachers find it challenging to write an appropriate quiz that can "generate significant thought without discouraging students from even addressing the questions (Cashman \& Eschenbach, 2003).”

Based on JiTT, Juang (2010a) developed a highly interactive learning model, WIRE, for blended learning, which integrates warm-up exercises before class, interaction in class, as well as review and exercise after class into a coherent learning experience. In the case study (Juang, 2010b), the warm-up strategy of WIRE model transforms the questioner from teacher to student. Namely, students must ask at least three questions in the warm-up assignments. Although the research results significantly alleviate both the teacher's heavy burden and difficulty of asking appropriate questions, superficial warmup exercises for students still persist. Since students can easily post questions for the preparatory assignment, they may not read the entire material or only pick up some ideas and post superficial questions to make perfunctory attempts.

By incorporating self-explanation theory (Lewis, 1988; McNamara, 2004; Chi, de Leeuw, Chiu, \& LaVancher, 1994; Chi \& VanLehn, 1991) and reading comprehension strategies (Robinson, 1970; Blachowicz \& Ogle, 2008), this work designs a lesson warm- 
up approach in which students can self-monitor their comprehension, explain what they read and question unclear portions of the assigned learning materials. A corresponding supporting system is constructed to implement the proposed approach in order to facilitate student awareness of the metacognition of learning management, ultimately improving the knowledge building process, including the recollection of previous knowledge, connection of old and new knowledge, and a greater understanding of new knowledge.

\section{Warm-up strategy design}

While emphasizing the restatement or explanation of learning material, self-explanation theory attempts to help individual knowledge construction (Lewis, 1988). By explaining one's understanding of a particular reading text either independently or under guided supervision, learners can construct improved mental models (Chi, de Leeuw, Chiu, \& LaVancher, 1994; Chi \& VanLehn, 1991). Through self-explanation, learners can increase their high-order thinking to bridge previous and new knowledge (McNamara, 2004). McNamara (2004) devised serial strategies to strengthen the self-explaining capability of students, including comprehension monitoring, paraphrasing, bridging inference, elaboration, using logic, and prediction. The training strategy improved students' reading skills through self-explanation and comprehension review of study materials. Chi and Vanlehn (1991) also suggested that through reading examples, students could generate more distinct constituent knowledge from their self-explanation capability and acquire general knowledge to complement incomplete principles and concept of the domain knowledge.

As for reading comprehension strategies, Robinson (1970) developed a study method SQ3R (survey, questioning, reading, reciting, and review) to raise reading comprehension. The previous three strategies are the major components for the warm-up assignments in this work. Also, based on the self-monitoring concept, Blachowicz and Ogle (2008) devised similar reading strategies used prior to, during, and after reading. Preview, prediction, questioning, checking understanding, monitoring understanding, and summarizing are helpful strategies for warm-up practices.

By applying the self-explanation theory and reading comprehension strategy, this work designs a warm-up strategy that can improve students' learning attitude, motivation, and learning effect to prepare for classroom activities. With the assistance of teacher's instructional messages and warm-up questions, the proposed strategy comprises four stages:

- Overview. Students are instructed to write an abstract of 100-150 words to provide an overview description and identify the major concepts of the class material after reading the text outline or introduction.

- Review prior knowledge. The teacher introduces previous concepts related to the new material, even providing related learning resources, for students to review prior knowledge and then rate the level of memory recall, based on five levels.

- Reading and comprehension monitoring. Students read either the digital or printed material. After reading, they are instructed to write a short, brief explanation within 200-300 words and ask questions and, finally, rate the level of comprehension, based on five levels.

- Summary. Students are instructed to take a quiz that comprises 3-5 warm-up 
multiple-choice questions, as provided by teachers for students to summarize and evaluate their preliminary understanding of the material. To thoroughly evaluate the status of the warm-up exercise, the students are instructed to answer a final question about their estimated time to complete the warm-up assignment.

\section{Supporting system design}

All activities related to the above stages are conducted online to ensure efficient interaction before classroom activities. Although any common course management system (e.g., Blackboard) can be used as a platform to implement the warm-up strategy, a custom designed system is an effective means of avoiding plagiarism during writing of the short brief and asking questions in the summary stage. Therefore, based on the above strategy, this work designs a web-based warm-up approach and incorporates it into a blog-based learning system (BBLS) (Juang \& Chan, 2009), which is originally designed to implement the WIRE model (Juang, 2010a).

\subsection{BBLS: Blog-based learning system}

BBLS combines teacher and student blogs into a learning space that starts by offering a course. Their relation can be illustrated as a three-dimensional structure (Fig. 1). Once a teacher creates a course, the system generates a teacher blog for that course and a student blog for each student enrolled in the course. While students can accumulate all learning portfolios such as warm-up, discussions, exercises, and homework, the teacher can undertake various online learning activities through blogging process details to accumulate teaching portfolios and pedagogical knowledge.

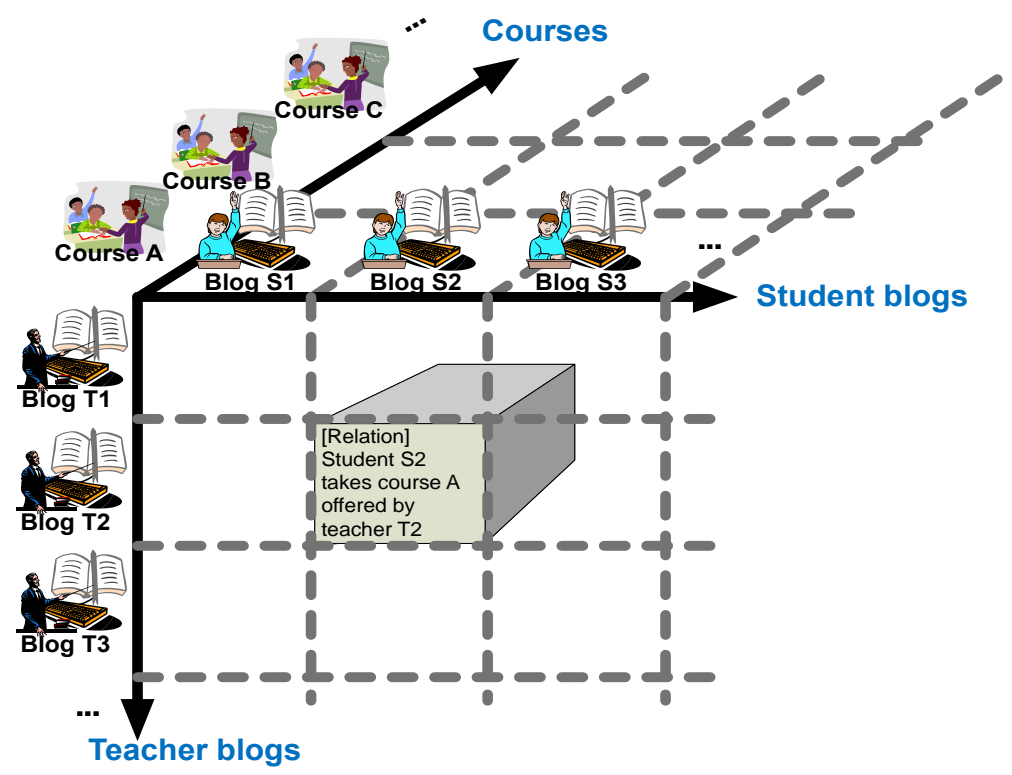

Fig. 1. Three-dimensional structure of BBLS, in which a learning space is created by incorporating both teacher and student blogs into a course 
BBLS provides various learning strategies based on the WIRE model, which comprises four stages in a learning flow: warm-up before class, interactive learning in class, and review and exercise after class. The teacher can initiate a learning flow by selecting a learning strategy to post the corresponding warm-up announcement article. All students are then notified to participate in learning activities formulated in the strategy. Each learning strategy has its own unique process and different productions of blogging. For instance, when the teacher posts a JiTT-like announcement, three multiplechoice questions and an open-ended question should be edited for the warm-up. The students must then answer these questions from their individual blogs without seeing other classmates' answers before classroom learning. When instructing in a classroom equipped with computers for group, the teacher can post an open-end question for group discussion. Each group should then use computers to answer the question in their group blogs for a follow up discussion or final summary. After class, all students are instructed to complete the puzzles or homework offered by teachers in their individual blogs. Finally, teachers assign scores and offer comment to each student.

\subsection{Tools design of warm-up by self-monitoring strategy}

According to the framework of BBLS the authors took advantage of the features of blogging to implement the self-monitoring warm-up strategy as a warm-up activity. The article of warm-up announcement edited by the teachers is structured as a form consisting of the lesson title, introduction to the topics, verification of prior knowledge, material uploading, and warm-up quiz (see Fig. 2)

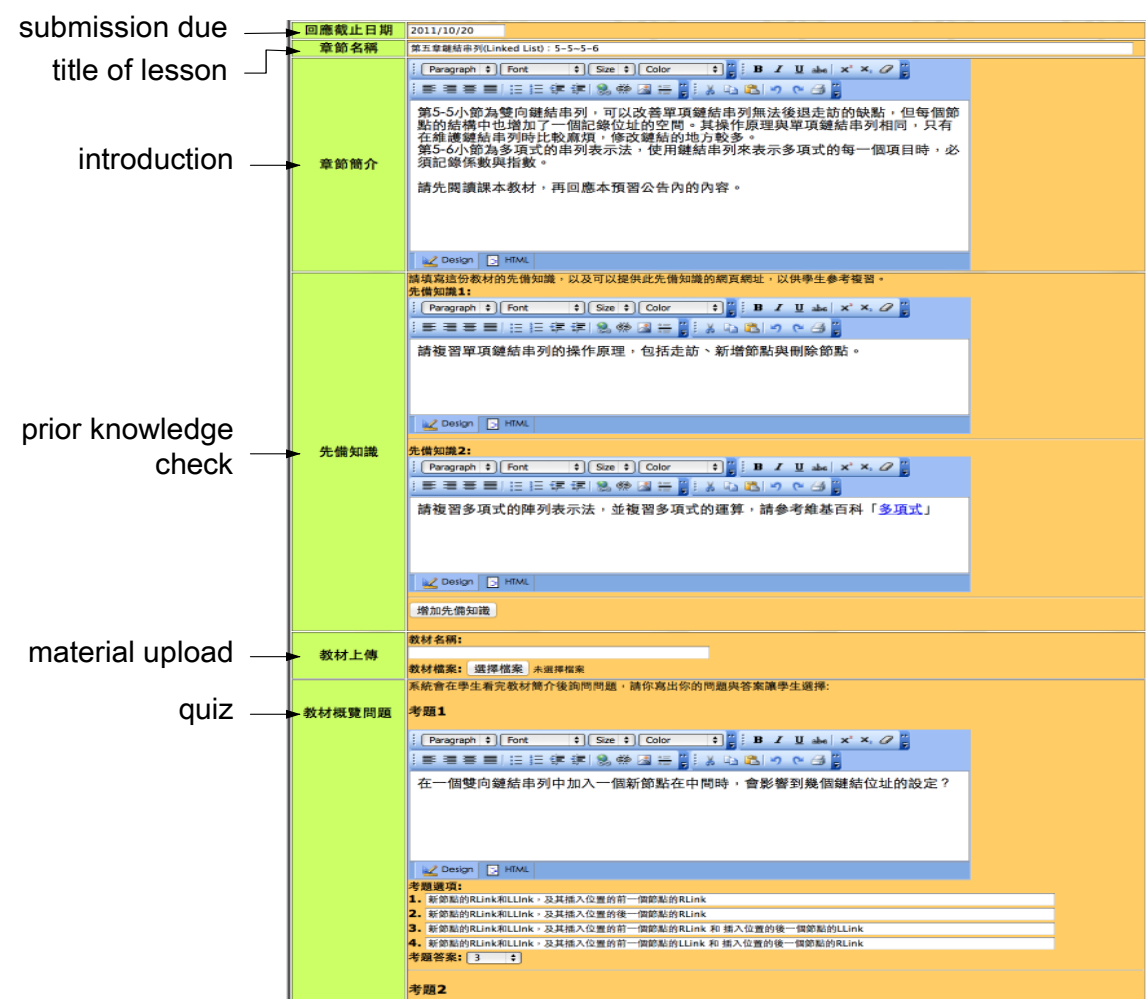

Fig. 2. Warm-up announcement as a form for teachers to fill out 
Once the warm-up announcement is posted, all students are notified by e-mail to start the warm-up process by replying to the warm-up article in their blogs. The reply article is also structured as a form in which content is composed from the teacher warmup announcement. The article comprises a lesson title, reply due date, introduction, familiarity with prior knowledge, understanding of materials, time of warm-up, warm-up quiz, summary of materials, and questions (see Fig. 3). This form guides students in connecting prior knowledge to new knowledge and self-monitoring their comprehension of assigned materials.

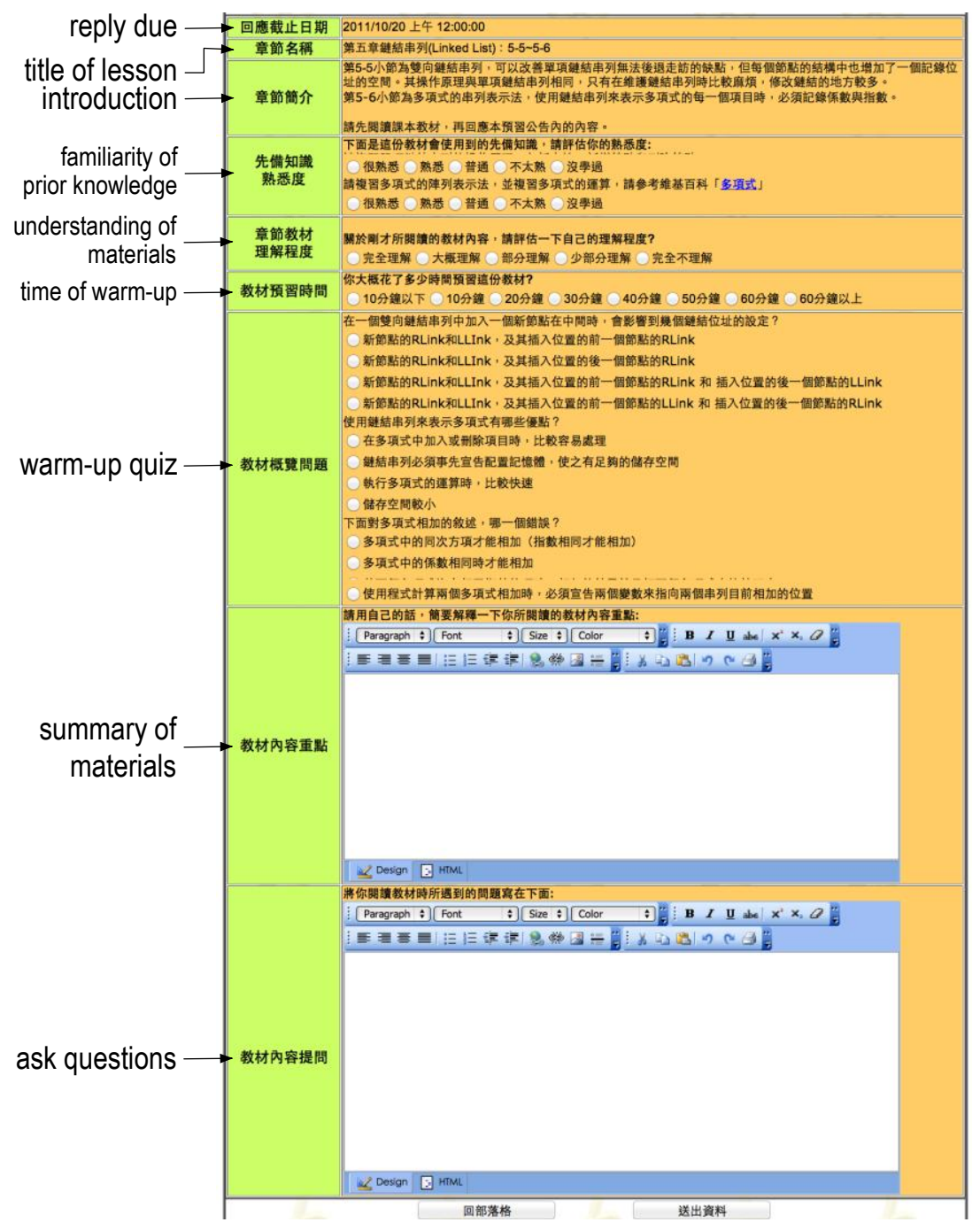

Fig. 3. Students' reply form for warm-up preparation

Furthermore, the system accumulates and summarizes all student replies into a statistical table to provide an overview of each student, including warm-up status, misconceptions, critical questions, and familiarity with materials. This data provides teachers with valuable information on how to adjust teaching methods and the degree of difficulty of learning materials for classroom activities. Also, the knowledge building 
process could be observed from this data to explain why students cannot follow up the learning steps. For instance, from the warm-up state of the first record in Fig. 4, the student was unfamiliar with the suggested prior knowledge, yet largely understood the new materials and positive performance on quiz (60\% correction) in his/her 40 minutes of warm-up time. The second record in Fig. 4 reveals a general understanding of the prior knowledge; however, the student only partially understood the new materials and performed poorly on the quiz (score of $40 \%$ ) in his/her 30 minutes warm-up time. Thus, the teacher may infer that the new material is weakly related to the previous knowledge; in addition, most students can preliminarily understand more than half of the new material $(56.4 \%$ on average).

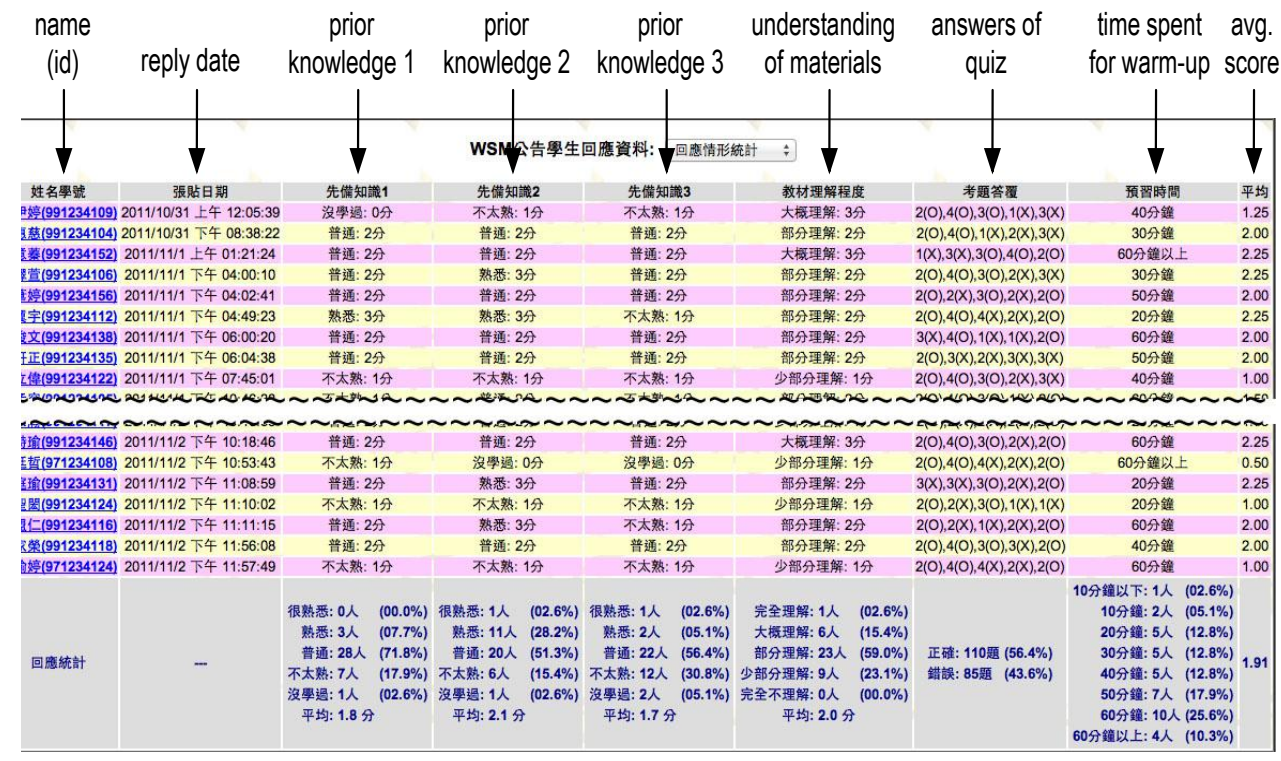

Fig. 4. Statistical table of warm-up states for all students

Closely examining the statistical data in Fig.4 revealed that students were familiar with prior knowledge 2 yet unfamiliar with prior knowledge 3 . Teacher should exert considerable effort on the recall of prior knowledge 3 . Additionally, most students failed on the fourth questions in the warm-up quiz, allowing teachers to infer that the concept or skill is difficult for students. Either learning content or teaching method should thus be adjusted.

\section{Teaching experiment and results}

\subsection{Teaching experiment design}

This work performed an experiment involving a sophomore year undergraduate class with 43 students for eight weeks to verify whether the self-monitoring warm-up strategy with the custom designed BBLS could enhance knowledge building. The participants took a pre-test and a post-test to evaluate improvements in learning and, then, filled out a questionnaire to evaluate the support in knowledge building. Finally, ten participants were selected to participate in a focus-group interview to obtain more detailed evidence. 
The pre-test was taken before the experiment to verify the initial capabilities of Java programming and basic algebra for learning the subject 'Data Structure,' which is a compulsory course in the Department of Information Management of their university. The post-test was taken after the experiment to compare the progress of learning achievement. The questionnaire was developed based on a 5-point Likert scale. All questions were categorized into three dimensions after factor analysis: recall of old knowledge, connection between old and new knowledge, and understanding of new knowledge. Three educational technology experts verified the validity of questionnaire to ensure well defined questions in order to examine the satisfactory evidence of the three aspects of support for knowledge building.

\subsection{Experiment results and discussion}

Average scores of the pre-test and post-test are 61.2 and 78.8 respectively, revealing a significant improvement $(\mathrm{p}<.001)$ in learning achievement through the $\mathrm{t}$-test verification. The questionnaire results in Table 1 reveal high satisfaction of students in all three dimensions, especially the dimension of understanding of new knowledge. Restated, most participants feel that the self-monitoring warm-up strategy with the custom designed tools in BBLS helped them achieve knowledge building in the warm-up preparation before class.

Table 1.

Questionnaire results

\begin{tabular}{|l|c|c|}
\hline \multicolumn{1}{|c|}{ Item dimensions } & $* \mathbf{M}(\mathbf{n = 4 3})$ & SD \\
\hline Recall of old knowledge & 3.94 & .574 \\
\hline Connection between old and new knowledge & 4.03 & .638 \\
\hline Understanding of new knowledge & 4.12 & .704 \\
\hline
\end{tabular}

* Using the five-point Likert scale, in which 1=strongly disagree and 5=strongly agree.

From the focus-group interview, most students $(80 \%)$ commented that the warmup strategy, which they had not experienced before, provides a great support in preparing lessons before classroom learning. Although the students spent additional time before class, the warm-up activities made the new materials more digestible and allowed them to more clearly understand the classroom lecture, even though they occasionally did not understand the new materials when reading by themselves. Furthermore, some interviewees $(60 \%)$ regarded the warm-up quiz as a facilitator in learning and thinking about concepts or skills presented in the new materials. This finding suggests that the knowledge building process was enlightened before class and would enhance understanding in classroom learning.

Some interviewees $(30 \%)$ felt that the time limit forces them to warm up lessons too quickly explaining why the rough reading of the materials led to low scores in the warm-up quiz, superficial reading of the abstract, and confusion over question-posting on BBLS. To understand this problem, the authors asked more questions related to the time that the students started to warm up and how problems were solved when they had questions. Each warm-up activity was regularly announced weekly and assigned at least 3 days in order to reply to the warm-up status on BBLS before the due date. The teacher could have announced the warm-up earlier or decreased the coverage of learning content. One interviewee suggested that BBLS should send an e-mail or short message to the 
students in order to remind them of the approaching warm-up deadline. However, during the interview the authors found those students who complained of an insufficient time to warm up lessons normally started to warm up two or three hours before the deadline, and they casually answered warm-up quiz answers and posted abstracts and questions without completely reading the entire assigned scope of the textbook or digital materials. Those students acknowledged not normally warming up before class in the past and that they were passive to learning independently. In sum, warm-up learning requires a more aggressive attitude towards managing one's personal schedule for learning.

Interviewees also commented that the warm-up quiz was slightly difficult to answer and might decrease students' confidence in reading new materials. Asking a good question is always a major challenge for teachers, especially questions that connect new knowledge to prior knowledge. We recommend that teachers develop quiz items by referring to the results of student pre-tests taken at the beginning of a course. All previous quiz results can also provide a valuable reference to evaluate student ability. Furthermore, in the warm-up stage, the cognitive objectives, from Bloom's taxonomy, should focus more on knowledge and comprehension, because the students only toughly perused the new materials and might have a weak understanding or misconceptions of the new learning content. They also did not have much time to thoroughly digest the materials for learning more about high-level cognitive abilities.

From the interview with the teacher, self-monitoring warm-up clarified the student warm-up status so that the teacher can adjust the learning content and teaching method precisely to achieve the optimum effect in classroom learning. The interaction between teacher and students and among students was obviously increased. The teacher received more students' attention during lectures and more motivation in group discussions. Although the preparation of warm-up announcement article took the teacher much time in preparation before class, it was worth getting the warm-up plan completed once, thus providing a valuable reference for qualitative teaching in the future.

\section{Conclusion}

Warm-up before class is widely recognized as an effective strategy to improve student engagement and understanding of classroom learning. However, the unclear status of preparation normally discourages teachers and students from maintaining a viable learning strategy. This work presents a novel self-monitoring warm-up approach with custom designed tools in a blog-based learning system to form mutual support between teacher and students. Students were given procedural guidance to prepare lessons and were motivated to monitor their understanding of new lesson contents. The teacher could then easily diagnose student warm-up statuses to adjust the learning contents and teaching methods in order to present the best instructions and produce best learning outcomes.

Results of a teaching experiment demonstrated that the teacher and students were highly satisfied with the proposed warm-up approach and corresponding tools. Although some challenges discouraged a small portion of the students, most of them strived their best to learn by using this warm-up method that they had not used previously. In using the system, students must learn how to arrange independently their time for warm-up practice. Although smaller warm-up materials and longer warm-up times could temporarily alleviate this problem, an aggressive learning attitude is essential to improving continuously. In using this system, teachers must design an appropriate quiz to connect new and old knowledge. Robust intelligent information systems could be 
designed to temporarily support decision. However, more practical experiences in diagnosing student abilities and evaluating their performances is vital to achieving a satisfactory outcome.

\section{Acknowledgements}

The authors would like to thank the National Science Council of the Republic of China, Taiwan, for financially supporting this research under Contract No. NSC 99-2511-S-228002-. Ted Knoy is appreciated for his editorial assistance.

\section{References}

Benedict, J. O., \& Anderton, J. B. (2004). Applying the just-in-time teaching approach to teaching statistics. Teaching of Psychology, 31(3), 197-199.

Blachowicz, C., \& Ogle, D. (2008). Reading comprehension: Strategy for independent learners. NY: The Guilford Press.

Cashman, E. M., \& Eschenbach, E. A. (2003). Active learning with web technology just in time! Proceeding of 33rd ASEE/IEEE Frontiers in Education Conference, T3F9-13.

Chi, M. T. H., de Leeuw, N., Chiu, M., \& LaVancher, C. (1994). Eliciting selfexplanations improves understanding. Cognitive Science, 18, 439-477.

Chi, M. T. H., \& VanLehn, K. A. (1991). The content of physics self-explanation. The Journal of the Learning Science, 1(1), 69-105.

Howard, J. R. (2004). Just-in-Time teaching in sociology or how I convinced my students. Teaching Sociology, 32(4), 385-390.

Juang, Y. R., \& Chan, J. (2009). Blog-based learning system: A tool for creating interactive learning portfolio. Proceedings of The 13th Global Chinese Conference on Computer in Education, 929-934.

Juang, Y. R. (2010a). WIRE: A blended model for teaching and learning in engineering curricula. In D.L. Russell \& A.K. Haghi (Eds.), Web-Based Engineering Education: Critical Design and Effective Tools (pp. 149-159). PA: IGI Global.

Juang, Y. R. (2010b). Blended learning in engineering curricula through the meaningful use of ICT tools. In A. Haghi \& R. Luppicini (Eds.), Cases on Digital Technologies in Higher Education: Issues and Challenges (pp. 202-216). PA: IGI Global.

Lewis, C. (1988). Why and how to learn why: Analysis-based generalization of procedures. Cognitive Science, 2, 211-256.

McNamara, D. S. (2004). SERT: Self-explanation reading training. Discourse Processes, 38(1), 1-30.

Novak, G. M., Patterson, E. T., Garvin, A. D., \& Christian, W. (1999). Just-in-time teaching: Blending active learning with web technology. Upper Saddle River, NJ: Prentice Hall.

Robinson, F. P. (1970). Effective study (4th ed.). New York, NY: Harper \& Row. 